\title{
MÍdIAS E EDUCAÇÃO: PROBLEMATIZANDO A FORMAÇÃO DOCENTE E OS DESAFIOS DA CIBERCULTURA
}

\author{
Joice Araújo Esperança ${ }^{1}$ \\ Marcio Vieira Oliveira ${ }^{2}$
}

\begin{abstract}
Resumo: Na atual configuração cultural, em que a mídia e o consumo ocupam centralidade nos processos de constituição de identidades e subjetividades, as escolas se deparam com desafios e dilemas que requerem repensar a formação docente. Partindo desse pressuposto, este artigo focaliza a articulação entre mídias e educação, problematizando o princípio da interatividade como característica distintiva dos modos de ser, viver e aprender que se engendram na atualidade. Apresenta reflexões desencadeadas no desenvolvimento de uma disciplina ofertada a cursos de Licenciatura, problematizando a abordagem teórico-metodológica que compõem sua proposta curricular e a análise de experiências pedagógicas desenvolvidas em quatro semestres letivos. Por fim, sinaliza alguns saberes docentes relacionados aos processos de ensino e aprendizagem no contexto da cibercultura.
\end{abstract}

Palavras-chave: Mídia-educação; cibercultura; saberes docentes.

\section{MEDIAS AND EDUCATION: ANALYZING AND QUESTIONING TEACHER TRAINING IN CYBERCULTURE BACKGROUND}

\begin{abstract}
In the contemporary cultural shaping in which media and consumption take up center position in the procedure of identity and subjectivity constitution, schools face challenges and impasses that require amends in teacher training. From there on, this article brings out the articulation between medias and education, problematizing the basic principle of interactivity as a distinctive attribute of the forged ways that people are, live and learn nowadays. This work exposes considerations triggered during a course offered in majoring, questioning the theoretical-methodological approach that is present in its curriculum and the detailed examination of the pedagogical experiences elements developed in four academic semesters. Finally, it indicates teaching knowledge towards teaching-learning processes in the cyberculture context.
\end{abstract}

Keywords: Media-education; cyberculture; teaching knowledge.

\footnotetext{
${ }^{1}$ Mestre e Doutora pelo Programa de Pós-graduação em Educação Ambiental, da Universidade Federal do Rio Grande (PPGEA/FURG) e graduada em Pedagogia. Professora do Instituto de Educação da FURG e do Programa de Pós-Graduação em Educação (PPGEDU). Líder do Grupo de Pesquisa Interdisciplinar "Tecnologias Digitais, Gestão e Formação Aplicadas a Educação - INTERFACES", ligado à Secretaria de Educação a Distância da FURG, onde desenvolve pesquisas sobre as temáticas Infâncias, Juventudes e Tecnologias Digitais, Educação a Distância e Formação Docente.

${ }^{2}$ Graduado em Comunicação Social, Hab. Jornalismo, pela Universidade Católica de Pelotas (UCPEL), Doutor em Educação em Ciências e Mestre em Educação Ambiental, pela Universidade Federal do Rio Grande (FURG). Técnico em Educação da Universidade Federal do Rio Grande e membro da Secretaria de Educação a Distância da FURG, onde integra o Grupo de Pesquisa Interdisciplinar "Tecnologias Digitais, Gestão e Formação Aplicadas a Educação - INTERFACES", atuando nos seguintes temas: Tecnologias da Informação e Comunicação na Educação Ambiental e na Divulgação Científica.
} 


\section{CONSIDERAÇÕES INTRODUTÓRIAS: REPENSAR A FORMAÇÃO DOCENTE E OS DESAFIOS DA CIBERCULTURA}

$\mathrm{Na}$ atual configuração cultural, em que a mídia e o consumo ocupam centralidade nos processos de constituição de identidades e subjetividades, as escolas se deparam com desafios e dilemas que requerem repensar a educação e a formação docente.

O entendimento de que os modos de ser e viver dos sujeitos são produzidos e modificados pelas condições histórico-culturais que caracterizam as sociedades, conduz à compreensão de que os principais aspectos implicados na construção das experiências das crianças e dos jovens na contemporaneidade - interações sociais, relações familiares, acesso à informação, atividades lúdicas e de entretenimento - são intermediados pelas mídias e suas linguagens (BUCKINGHAM, 2007; BELLONI, 2012).

Entretanto, mesmo desconsiderando as práticas culturais compartilhadas por estudantes imersos numa sociedade que tem a mídia e o consumo como princípios organizadores, os professores precisam lidar com seus efeitos: as crianças e os jovens chegam as salas de aula educados por programas de televisão, os quais moldam suas referências e visões de mundo; acessam artefatos audiovisuais e hipertextos desde a mais tenra idade, desenvolvendo novas capacidades, saberes e modos de aprender; para essas crianças os limites físicos da escola e das salas de aula, não raras vezes, parecem pouco atrativos, diante do espaço desterritorializado e sem fronteiras experimentado por meio da internet, o qual disponibiliza a todas as classes de idade a mesma informação (ESPERANÇA, 2013).

Sob tais circunstâncias, justifica-se a relevância de pesquisas interessadas em compreender as mídias como práticas culturais e suas imbricações com os currículos escolares. Acreditamos que conhecer as experiências dos estudantes com as mídias e pensar a inserção dessa temática na formação de professores suscita instigantes possibilidades de reflexão e ação pedagógica, criando possibilidades para problematizarmos, conceituarmos e propormos perspectivas que aproximem a escola das expectativas dos estudantes, promovendo leituras e usos críticos e criativos das mídias, que associem linguagens e modos de expressão emergentes na contemporaneidade.

Partindo desses pressupostos, neste artigo focalizamos a articulação entre mídias e educação, problematizando o princípio da interatividade como característica distintiva dos modos de viver e aprender que se engendram na atualidade. Apresentamos reflexões desencadeadas no desenvolvimento de uma disciplina ofertada a cursos de Licenciatura da Universidade Federal do Rio Grande (FURG), problematizando a abordagem teórico- 
metodológica que compõe sua proposta curricular e a análise de experiências pedagógicas desenvolvidas no decorrer de quatro semestres letivos. Por fim, discorremos sobre alguns saberes docentes relacionados aos desafios educacionais emergentes no contexto da cibercultura.

\section{A DISCIPLINA MÍDIAS E EDUCAÇÃO E SUA PROPOSTA CURRICULAR: ABORDAGEM TEÓRICO-METODOLÓGICA E OBJETIVOS FORMATIVOS}

Nesta seção buscamos contextualizar a disciplina Mídias e Educação e sua proposta curricular, situando a abordagem teórico-metodológica, isto é, as concepções e os fundamentos pedagógicos que orientam a seleção e o tratamento dos conteúdos, o delineamento de objetivos formativos e o planejamento de estratégias metodológicas. $\mathrm{Na}$ sequência, caracterizamos o grupo de estudantes que participaram das últimas edições da disciplina, ofertadas entre os anos de 2012 e 2016.

A disciplina Mídias e Educação é vinculada ao Instituto de Educação, da Universidade Federal do Rio Grande (FURG), localizada no município de Rio Grande/RS. A referida disciplina é ofertada em caráter optativo aos acadêmicos dos cursos de Licenciatura e possui carga horária semanal de $4 \mathrm{~h} /$ aula durante um semestre letivo. Nas últimas edições, as turmas foram integradas por estudantes dos cursos de Pedagogia e Artes Visuais ${ }^{3}$. A tabela abaixo permite visualizar o total de matrículas realizadas entre os anos de 2012 e 2016 e o número de estudantes por curso.

Tabela 1 - Número de estudantes conforme os cursos e os anos de oferta da disciplina.

\begin{tabular}{|c|c|c|c|}
\hline Ano & Pedagogia & $\begin{array}{c}\text { Artes } \\
\text { Visuais }\end{array}$ & $\begin{array}{c}\text { Total de } \\
\text { Estudantes }\end{array}$ \\
\hline 2012 & 24 & 6 & 30 \\
\hline 2013 & 0 & 8 & 8 \\
\hline 2014 & 22 & 2 & 24 \\
\hline $2016 \mathrm{~A}$ & 35 & 1 & 36 \\
\hline $2016 \mathrm{~B}$ & 19 & 1 & 20 \\
\hline
\end{tabular}

Fonte: Arquivo pessoal dos pesquisadores.

A ementa da disciplina prevê o estudo das articulações entre mídias, culturas e educação; o pensar sobre as mídias e a constituição das infâncias e das juventudes na contemporaneidade; a problematização acerca dos processos de ensino-aprendizagem

\footnotetext{
${ }^{3}$ A oferta de disciplinas optativas requer solicitação por parte das coordenações de cursos. Sendo assim, somente os cursos de Artes Visuais e Pedagogia realizaram a solicitação de oferta da disciplina Mídias e Educação nos períodos letivos focalizados neste artigo.
} 
potencializados pelas mídias e suas linguagens; a análise de possibilidades de integração das mídias nas propostas pedagógicas; a discussão acerca dos princípios da interatividade, dos ambientes virtuais de aprendizagem (AVA) e do processo de produção de material didático digital e a reflexão sobre a relação entre mídias e escola, considerando possibilidades e perspectivas educacionais.

Para situarmos a organização curricular da disciplina Mídias e Educação consideramos necessário definir o que compreendemos por currículo e suas implicações para a formação dos sujeitos. Entendemos que o currículo de uma disciplina ou de um curso estabelece relações com a cultura e a sociedade, portanto, que qualquer forma de organização curricular ancora-se num conjunto de expectativas de formação, que diz respeito as transformações que desejamos efetuar nos estudantes, aos valores que almejamos inculcar nos sujeitos, às identidades que pretendemos construir (MOREIRA e CANDAU, 2007). Portanto, além dos conteúdos formalizados na Ementa da disciplina Mídias e Educação, a seleção de unidades ou de temáticas para estudo, as perspectivas teóricas que pautam as análises dos conteúdos, assim como o planejamento das estratégias metodológicas, configuram escolhas intencionais e articuladas que integram a organização curricular da disciplina. Em suas diversas dimensões, tal organização curricular visa atingir algumas finalidades ou objetivos educacionais, relacionados à dinâmica mais ampla da sociedade e as respectivas demandas de formação docente.

Nesse sentido, orientados pela perspectiva dos Estudos Culturais, buscamos potencializar entre os estudantes, futuros docentes, a reflexão acerca das mídias como instâncias produtoras de significados, atentando para as conexões entre poder, verdade e identidade (SILVA, 1999). Subsidiados por esse aporte teórico-conceitual, pretendemos formar profissionais da educação atentos às mudanças culturais em curso, capazes de promover situações didáticas que potencializem aprendizagens de forma crítica e interativa, integrando diversas mídias e linguagens presentes na vida em sociedade ao ensino dos conhecimentos escolares.

Nossa perspectiva de análise acerca da centralidade da mídia e seus efeitos na sociedade contemporânea coaduna-se com as considerações de Kellner (2001) sobre como as produções midiáticas colaboram para moldar visões prevalecentes de mundo, definindo o que é certo ou errado, moral ou imoral. Ainda de acordo com o autor, os significados construídos e socializados pelas mídias, em seus diversos formatos, fornecem os parâmetros segundo os quais muitas pessoas constroem seu senso de nacionalidade, classe, raça/etnia, sexualidade, etc. Nesse sentido, 
Para quem viveu imerso, do nascimento à morte, numa sociedade de mídia e consumo é, pois, importante aprender como entender, interpretar e criticar seus significados e suas mensagens. Numa cultura contemporânea dominada pela mídia, os meios dominantes de informação e entretenimento são uma fonte profunda e muitas vezes não percebidas de pedagogia cultural: contribuem para nos ensinar como nos comportar e o que pensar e sentir, em que acreditar, o que temer e desejar - e o que não (KELLNER, 2001, p. 10).

Nessa direção, buscamos selecionar conceitos para estudo e planejar situações didáticas que instiguem os licenciandos a analisarem e compreenderem os mecanismos por meio dos quais a mídia se organiza e opera na vida em sociedade. Paralelamente, os acadêmicos são provocados a interpretar textos da mídia, como propagandas, filmes, revistas, sites, músicas, aplicativos, etc. e a avaliarem os potenciais efeitos dessas produções na formação das crianças e dos jovens que frequentam as salas de aula hodiernas. Cabe ressaltar que tais escolares desconhecem o mundo sem a presença de mídias como a televisão e os dispositivos móveis conectados à internet, que lhes apresentam, desde a mais tenra idade, interpelações ao consumo de bens e serviços, "influenciando o modo como [...] pensam e se comportam, como se veem e veem os outros e como constroem sua própria identidade" (KELLNER, 2001, p. 10).

Importa ainda salientar que as situações didáticas propostas pautam-se numa concepção ampla de cultura que questiona as convencionais distinções entre a chamada "alta cultura" - a cultura erudita, ou relacionada às formas de expressão das classes privilegiadas, caracterizadas como cultas - e a "baixa cultura" - isto é, os significados e expressões da cultura popular, compartilhados por grupos minoritários em termos de poder simbólico. Entretanto, questionar as diferenças e tensões entre as expressões da alta cultura e da cultura popular não implica, como adverte Fischer (2003, p. 26), assumir um entendimento indiscriminado de cultura. Sendo assim, compreendemos que "falar em cultura implica em falar de um campo muito específico, qual seja, o da produção histórica e social de significações numa determinada formação social. Tal produção é complexa, diversificada e sempre implica relações de poder".

Ao interpretarmos textos culturais representativos de diversos grupos sociais, tais como diferentes gêneros musicais e literários, propagandas, programas de televisão, filmes, obras de arte, revistas direcionadas a públicos heterogêneos, etc., problematizamos as relações de poder que implicam distinções hierárquicas entre essas produções, incentivando os estudantes a repensarem ideias preconcebidas. Assim, questionamos a primazia de algumas formas de expressão cultural sobre outras, enfatizando e explicitando 
as incontestes imbricações entre a produção cultural e o sistema econômico, político e social. Além disso, buscamos problematizar os contextos de vivência em que os significados são consumidos e interpretados, colocando à prova "o entendimento vertical e linear dos processos culturais" (FISCHER, 2003, p. 8), como se a mídia agisse de forma determinante sobre os sujeitos, desconsiderando-se os efeitos de outras experiências e instâncias de socialização.

A ênfase das mídias como instâncias produtoras de significados, como meios de circulação e troca cultural, também está atrelada à tentativa de superação da perspectiva instrumental, que circunscreve a compreensão das mídias como recursos ou suportes ao ensino dos conteúdos escolares. Nessa perspectiva, as mídias servem apenas para "ilustrar" conceitos, tornando as aulas, presumidamente, mais atrativas por meio do emprego de equipamentos que, por si sós, são incapazes de superar abordagens e metodologias tradicionais de ensino, pautadas na repetição, na cópia e centradas na figura do professor. Sem desconsiderar a importância de que os estudantes desenvolvam competências instrumentais ou técnicas relativas ao uso das mídias, acreditamos que tais aprendizagens devem ser desenvolvidas em articulação com a leitura crítica da mídia e de sua inserção na dinâmica mais ampla da sociedade.

Portanto, na tentativa de articularmos as dimensões instrumentais e pedagógicas das mídias e de suas linguagens propomos a leitura e a interpretação crítica de alguns textos culturais atreladas a produções individuais e coletivas, as quais são desenvolvidas e socializadas pelos estudantes por meio de ferramentas interativas, como blogs, grupos criados no site da rede social facebook e fóruns de discussão no AVA criado na plataforma institucional (Moodle). Com essa abordagem, os estudantes têm a possibilidade de experienciarem formas de aprendizagem emergentes no contexto da cibercultura (LÉVY, 1999), em que as práticas comunicacionais têm a potencialidade de superar a unidirecionalidade das mídias clássicas, oportunizando dinâmicas dialógicas e interativas, capazes de associar emissão e recepção como polos complementares na construção e na socialização conjunta do conhecimento (SILVA, 2008).

Após situarmos alguns dos princípios teórico-metodológicos que pautam a organização curricular da disciplina Mídias e Educação, na próxima seção apresentamos a análise de algumas situações didáticas desenvolvidas com os estudantes, problematizando os processos de ensino e aprendizagem estabelecidos em sala de aula, seus limites e possibilidades. Trata-se de uma abertura à reflexão sobre o exercício da docência no ensino 
superior, visando a construção e a socialização de saberes da ação pedagógica 4 (GAUTHIER, 1998). Nosso esforço também recai sobre o desafio urgente e oportuno de repensar o âmbito da formação de professores, seus dilemas e tensões no contexto da cibercultura, que coloca à disposição dos sujeitos múltiplas linguagens e diversos canais de comunicação, possibilitando a construção de aprendizagens de forma colaborativa, interativa e hipertextual e promovendo o intercâmbio de saberes para além dos espaços formais de ensino.

\section{COMO VOCÊ VIVERIA NUM MUNDO SEM MÍDIAS? PROBLEMATIZANDO OS MODOS DE VIVER E APRENDER DOS ESTUDANTES DA GERAÇÃO DIGITAL}

Para inaugurarmos a reflexão acerca das mídias e a constituição das infâncias e das juventudes na contemporaneidade, item que integra a Ementa da disciplina, desenvolvemos com as turmas uma atividade em duplas, que consiste na resposta à seguinte questão:

As mídias estão presentes em nosso cotidiano, possibilitando acesso a informação, a comunicação e a formas de entretenimento diversificadas. Você já pensou como seria sua vida sem acesso as mídias?

Após apresentarmos o questionamento mencionado acima ${ }^{5}$, é possível constatar a estupefação dos acadêmicos, uma agitação toma conta do espaço da sala de aula, contemplando estudantes de todas faixas etárias. Observamos que os mesmos passam a dialogar paralelamente acerca da indagação, a qual parece provocar-lhes um sentimento de desconforto, facilmente perceptível. Na sequência, disponibilizamos materiais para desenho, pintura, recorte e colagem e solicitamos aos estudantes que expressem suas respostas de forma escrita e/ou através de imagens.

As imagens abaixo expressam alguns dos sentidos comunicados pelos acadêmicos em suas produções:

\footnotetext{
${ }^{4}$ De acordo com Gauthier (1998) os saberes da ação pedagógica são os saberes experienciais a partir do momento em que se tornam públicos, socializados, através de pesquisas ou publicações, quando a jurisprudência particular do professor, suas análises e estratégias bem-sucedidas, podem ser comparadas, avaliadas e a partir delas pode-se estabelecer "regras de ação" ou saberes que poderão ser conhecidos por outros professores.

${ }^{5}$ Esta atividade foi inspirada na pesquisa realizada por Don Tapscott, publicada na obra "A hora da geração digital”, em que o autor questiona jovens integrantes da geração digital sobre como eles se sentiriam sem acesso as tecnologias de informação e comunicação.
} 


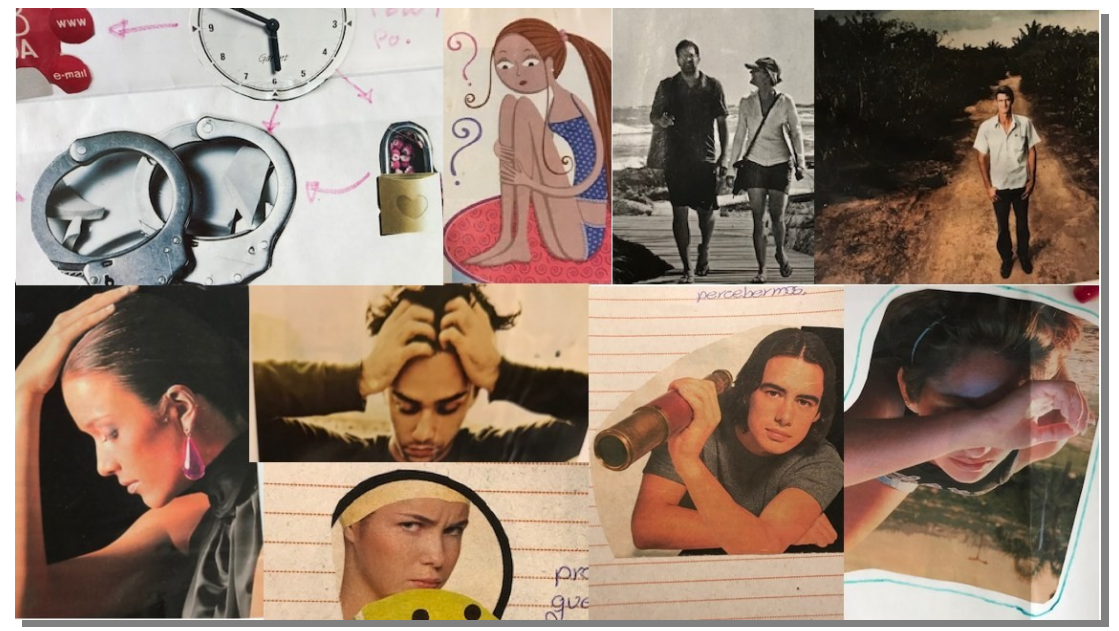

Figura 1: Como você viveria sem acesso as mídias? (A) Fonte: Arquivo pessoal dos pesquisadores.

Ao elaborarem suas composições, mesclando imagens e escritas, os estudantes registram alguns vocábulos que expressam sentimentos de desconforto, tais como: "isolamento", "falta de perspectiva", "estranhamento", “depressão", "tristeza”, "falta", "ausência", "aborrecimento", "tédio", entre outras palavras que demonstram a dificuldade e o desafio de imaginar a própria vida sem a presença dos meios de informação e comunicação.

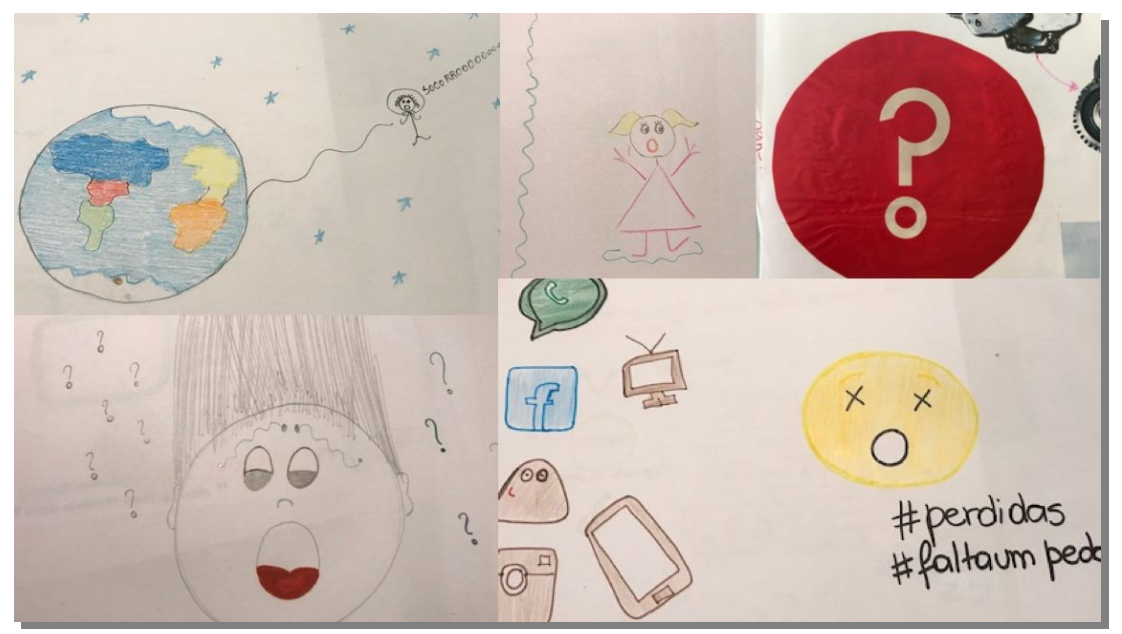

Figura 2: Como você viveria sem acesso as mídias? (B) Fonte: Arquivo pessoal dos pesquisadores.

Nas imagens reunidas acima um dos estudantes chega a sinalizar um pedido de "socorro", de um sujeito que parece estar "desconectado do mundo". Os acadêmicos também comunicam suas respostas por meio de imagens que reproduzem expressões faciais de espanto e pavor ou, ainda, através de um enorme ponto de interrogação, que sugere a dúvida não resolvida ao pensarem numa possível resposta para a pergunta lançada. Duas estudantes descreveram-se como "perdidas" e apontaram a "falta de um 
pedaço" diante da ausência das mídias em seu cotidiano. Nessa produção é interessante observar que as acadêmicas reproduziram ícones de aplicativos e de sites de redes sociais, tecnologias móveis, mas também uma mídia clássica: a televisão. Em tal desenho chama atenção o emprego de hashtags, como marcas da linguagem compartilhada na internet, em sites de redes sociais, e que permitem a criação de hiperlinks que operam como mecanismos de busca e indexação.

Esta atividade têm desdobramentos profícuos: em primeiro lugar, possibilita integrar a turma, tendo em vista que promove a socialização de sentidos e sentimentos acerca de experiências vivenciadas por todos; em segundo lugar, a atividade desencadeia a problematização acerca dos modos de viver e aprender levados a cabo pelas mídias digitais e a integração de linguagens na contemporaneidade, aspecto ainda desconsiderado por grande parte das instituições formais de ensino. Nesse sentido, é interessante reproduzir o registro de um questionamento elaborado por duas estudantes: "A sociedade mudou tanto com a evolução das mídias... E a escola, mudou? Tem que mudar".

A partir do convite à reflexão sobre a impossibilidade de viver sem acesso as mídias, conclusão unânime entre os acadêmicos das turmas que cursaram a disciplina entre os anos de 2012 e 2016, introduzimos o estudo dos conceitos de grupos geracionais, infâncias e juventudes, destacando as modificações nos modos de subjetivação e de aprendizagem. A reflexão acerca dos referidos conceitos encaminha o repensar sobre as práticas escolares, conforme apontado acima pelas estudantes quando reforçam as conexões entre escola e sociedade e reiteram a necessidade de que a escola acompanhe as transformações operadas nas formas de produção, circulação e consumo de significados na sociedade contemporânea.

De acordo com Bauman (2013), embora nenhum ser humano seja igual a outro é possível observar em algumas categorias de sujeitos atributos ou características que tendem a se sobressair com maior frequência que em outras. Nessa direção, o autor define as gerações, assim como os pertencimentos de classe, gênero e nação, como “condensações relativas", o que nos leva a desconsiderar a pluralidade e as idiossincrasias que fazem de cada sujeito um ser único e nos determos nos aspectos comuns a todos ou à maioria dos integrantes de uma categoria, neste caso, dos sujeitos que nasceram, viveram e compartilharam modos de socialização num mesmo período histórico. Com base nessas considerações, propomos aos estudantes a reflexão acerca das características da chamada “geração digital” (TAPSCOTT, 2010), que figura nas análises de Bauman (2013) com a denominação de "geração Z”. Entre as características apontadas pelas pesquisas estudadas 
nos encontros da disciplina Mídias e Educação, concluímos que trata-se de uma geração que nasceu a partir da última década do século $\mathrm{XX}$, num mundo permeado por incontáveis opções, numa sociedade regulada pelo consumo exacerbado, pela efemeridade, descartabilidade e velocidade, características que foram potencializadas pela evolução das mídias e pela criação da rede mundial de computadores, que instituiu o princípio da interatividade como mudança no esquema clássico de comunicação (SILVA, 2004).

\section{APRENDER E ENSINAR NO CIBERESPAÇO: A CONSTRUÇÃO DE BLOGS E AS INTERAÇÕES NO AMBIENTE VIRTUAL DA DISCIPLINA}

Além de atividades dialógicas e mobilizadoras de reflexões sobre as vivências dos acadêmicos com as mídias, relacionando suas percepções e sentimentos com os conceitos estudados e analisados na disciplina, buscamos ampliar as interações para além do espaço físico da sala de aula, criando um AVA em nossa plataforma institucional (Moodle). Compreendemos os ambientes virtuais como potencializadores de aprendizagens quando possibilitam interações entre os sujeitos aprendentes, criando oportunidades de participação, autoria e protagonismo no contexto de uma experiência formativa, como no caso da disciplina em questão. Tais ambientes virtuais, articulados às relações entre professores, conteúdos e estudantes, construídas na sala de aula presencial, são capazes de reduzir a distância comunicacional no processo didático, além de ampliar as possibilidades de significação acerca dos objetos de conhecimento. Sob essa ótica de pensamento, Santos e Okada (2003, p. 2-3) esclarecem:

[...] um ambiente virtual é um espaço fecundo de significação onde seres humanos e objetos técnicos interagem potencializando assim, a construção de conhecimentos, logo a aprendizagem. [...] Então, todo ambiente virtual é um ambiente de aprendizagem? Se entendermos aprendizagem como um processo sócio-técnico onde os sujeitos interagem na e pela cultura sendo esta um campo de luta, poder, diferença e significação, espaço para construção de saberes e conhecimento, então podemos afirmar que sim.

Pautados por essas compreensões, no AVA da disciplina propomos algumas variações de fóruns, dentre os quais destacamos: fórum de uma única discussão, fórum de criação de tópicos de discussão, fórum geral e de perguntas e respostas. Em todas as propostas, a condição de expressar-se e de interagir com os colegas e com os professores são princípios pedagógicos que atuam de forma articulada. Abaixo apresentamos a imagem que demonstra a proposição de uma discussão que requer dos estudantes pensarem acerca 
de suas experiências e sobre os modos como as mídias permeiam seu cotidiano. Além disso, solicitamos a escolha de, pelo menos, um colega para interação, além do diálogo com os professores a partir das contribuições compartilhadas.

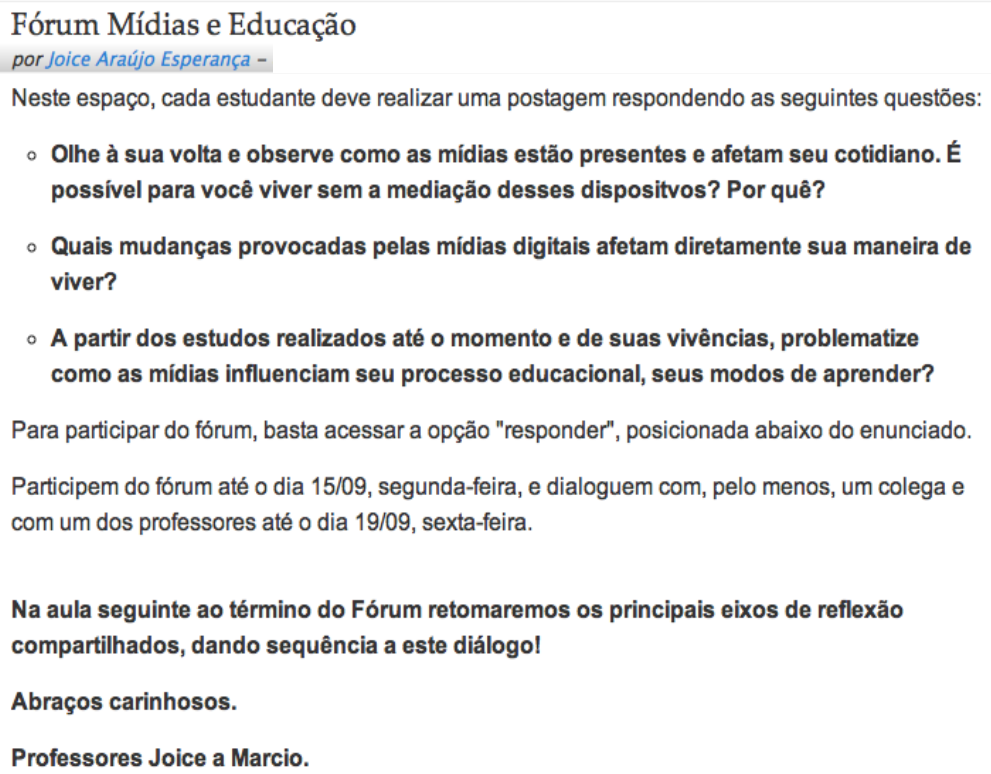

Figura 3: Fórum de discussão Mídias e Educação Fonte: Arquivo pessoal dos pesquisadores.

Em relação aos critérios citados no enunciado do fórum, destacamos nossa intencionalidade pedagógica quando instituímos como critério de avaliação o diálogo entre colegas e professores. Este critério foi estabelecido após constatarmos a resistência dos estudantes em retornarem ao fórum para dialogar. Desse modo, percebemos que a interação não se estabelecia, permanecendo a unidirecionalidade no processo comunicacional, o qual se resumia a estudantes e professores na forma de uma resposta individual desencadeada por um enunciado. A partir dessa constatação identificamos a necessidade de estudarmos e vivenciarmos a interatividade em nosso ambiente virtual. Sendo assim, explicamos aos licenciandos nossa intencionalidade quando solicitamos a participação e buscamos promover a dialogicidade nos fóruns. Problematizamos junto aos estudantes, a partir dessa situação, que se repete em todas as edições da disciplina analisadas até aqui, o quanto nossa tradição escolar, pautada na construção individual do conhecimento, centrada na figura do professor e com pouco estímulo a autonomia e a criação no processo de aprendizagem, desencadeia posturas como as que percebemos ao analisarmos o modo como os acadêmicos atuam em suas primeiras aproximações com o AVA da disciplina. 
Podemos afirmar que o estudo dos conceitos de ciberespaço ${ }^{6}$, comunicação e interatividade, realizados por intermédio das produções de Lévy (1998; 1999) e Silva (2004; 2008) e a necessidade de revisitar o espaço virtual de discussão em que se constitui cada fórum proposto, desencadeia, ao longo do semestre letivo, mudanças significativas nas ações de participar e interagir realizadas pelos estudantes. Conforme Silva (2008), a interatividade pressupõe participação-intervenção, sendo que participar vai além de responder sim ou não ou escolher entre opções, mas supõe, sobretudo, "interferir no conteúdo da informação e modificar a mensagem" (p. 70). Além disso, o autor esclarece a necessidade de bidirecionalidade e hibridização no processo comunicativo para que a interatividade se efetive, sendo assim, a comunicação torna-se produção coletiva. Nessa linha de pensamento, Lévy (1998) elucida que o ciberespaçopotencializa formas de comunicação que superam o esquema "um para todos", em que um centro emissor produz e distribui mensagens aos receptores, sem promover reciprocidade e interação, embora constitua um sentido de comunidade entre aqueles que compartilham do mesmo conteúdo. Em suas palavras:

O ciberespaço [...] permite, ao mesmo tempo, a reciprocidade na comunicação e a partilha de um contexto. Trata-se de comunicação conforme um dispositivo "todos para todos". [...] Como todas as mensagens são registradas, sedimenta-se assim progressivamente uma memória, um contexto do grupo de discussão. Cabe salientar que essa memória, esse contexto comum, em vez de vir de um centro emissor Todo-Poderoso, emerge da interação entre os participantes (p. 43-44)

O progressivo envolvimento dos estudantes com as proposições de debates e reflexões propostas nos fóruns, atrelado a apropriação dos conceitos estudados, reflete-se na densidade das postagens e nas aprendizagens construídas acerca das tecnologias e seus impactos no cenário contemporâneo. Ademais, percebe-se entre os acadêmicos que já atuam como professores o gradativo desenvolvimento da capacidade de mobilizar os conceitos estudados para analisarem suas trajetórias de aprendizagem, suas experiências e suas práticas pedagógicas. Isso fica evidente quando os estudantes/professores mencionam nos fóruns a mudança nos processos didáticos que desenvolvem nas escolas, a ressignificação dos saberes docentes e das relações com as crianças e os jovens, demonstrando que as aprendizagens construídas na disciplina têm efeitos sobre suas práticas.

\footnotetext{
${ }^{6}$ De acordo com Lévy (1999), o ciberespaço é o espaço de comunicação, sociabilidade e compartilhamento de informações aberto pela interconexão mundial dos computadores. $\mathrm{O}$ ciberespaço também é definido por Lévy como o principal canal de comunicação e suporte de memória da humanidade no século XXI.
} 
Desde o começo da civilização não é possível conviver sem as tecnologias de cada época. Nos tempos atuais as novas tecnologias estão ligadas associadas aos modelos da informática, internet, robótica e nanotecnologias. Quando observamos na nossa volta, vários detalhes tecnológicos nos cercam e vão se tornando extremamente necessários, como por exemplo: o telefone celular, tablet, smarphones, sites de busca como o Google entre outros que vão nos dando novos horizontes para que possamos pensar nosso lugar no mundo e dos demais seres com os quais nos comunicamos de diversas formas, tanto presenciais, quanto virtuais. Ambas reais e com suas concretudes, com sutilezas de afetos e pertencimentos. As tecnologias tem influenciado o meu processo educacional por colocar a questão da interatividades entre meus alunos, que me adicionam no Facebook, como uma forma de nos conhecermos de outras maneiras, que a apresentação formal do primeiro dia de aula. Dessa maneira, eu vasculho todas as fotografias deles, suas postagens, seus amigos e outras apresentações, que vão me dando um parâmetro de como mediar a sala de aula. Além deste fato, a preparaç̃o da aula torna cada vez mais necessário entrar em diversas páginas, como o Yahoo, os jornais digitais, que fornecem elementos de chamada da atenção, para provocar a atenção dos alunos. De outra parte, a troca de e-mails, de posts, o compartilhamento de mensagens criam um novo ambiente de trocas de relações inovadoras com o conhecimento. Como estudante de Pedagogia, sofro a influência de novas tecnologias em meu processo de formação acadêmica, vindo dos professores, dos colegas e de acadêmicos dos outros cursos da Furg. Toda essa rede é impressionante e dinâmica, que nos faz reencontrar pessoas, reviver experiências e reinventar a percepção do meu cotidiano.

Figura 4: Postagem de estudante no Fórum de discussão. Fonte: Arquivo pessoal dos pesquisadores.

Conforme destacamos no início deste artigo, ao caracterizarmos e definirmos a organização curricular da disciplina Mídias e Educação, durante as aulas promovemos análises de diversos artefatos midiáticos, promovendo a articulação entre linguagens. Dentre os procedimentos de análise empregados no desenvolvimento da disciplina, destacam-se a audiência e o debate acerca de vídeos sobre temas contemporâneos, tais como infâncias, juventudes e consumo e tecnologias digitais na escola; a leitura crítica de propagandas veiculadas na televisão ou em revistas impressas ${ }^{7}$; o planejamento de situações didáticas a partir da abordagem de produções audiovisuais da TV aberta como capítulos de seriados amplamente consumidos por crianças e jovens brasileiros; a análise reflexiva de músicas, poesias, documentários e sites da internet, problematizando seu potencial pedagógico; a elaboração de um livro digital com o registro das aprendizagens construídas na disciplina Mídias e Educação.

Para integrar as produções mencionas acima e torna-las acessíveis a outros estudantes, professores, pesquisadores e qualquer internauta interessado no estudo das

\footnotetext{
${ }^{7}$ A leitura crítica de propagandas veiculadas na televisão e em revistas impressas é realizada com base no estudo das estratégias ou "modos de endereçamento", conforme os estudos de Elizabeth Ellsworth (2001) e de Rosa Maria Bueno Fischer (2003).
} 
relações entre mídias e educação, os estudantes constroem blogs ${ }^{8}$ na perspectiva de portfólios digitais. Nessa abordagem, os blogs são utilizados para o registro das trajetórias de aprendizagem trilhadas pelos acadêmicos, através da postagem das produções elaboradas ao longo do semestre. Assim, mais do que um simples recurso, o blog é concebido e configura-se como uma estratégia pedagógica que possibilita aos estudantes o envolvimento em processos de autoria e criação. De acordo com Gomes e Lopes (2007, p. 123),

A exploração dos blogues dentro dessa perspectiva, transforma-os, mais do que num recurso pedagógico, numa estratégia de ensinoaprendizagem, que visa conduzir os alunos a atividades de pesquisa, seleção, análise, síntese e publicação de informação, com todas as potencialidades educacionais implicadas.

Sendo assim, os blogs se articulam à proposta curricular da disciplina que prevê a integração entre diversas formas de expressão e linguagens. Em seus blogs os estudantes podem reunir textos escritos, imagens, músicas, vídeos, dentre outras produções e materiais analisados, além de disponibilizarem hiperlinks para acesso a reportagens, documentários e filmes, por exemplo.

Ao longo do semestre são realizadas diversas oficinas para construção e atualização dos blogs ${ }^{9}$. Na primeira aula cujo objetivo consiste na criação do blog, solicitamos à turma que se organizem em duplas ou trios. Optamos por essa estratégia visando reduzir a ansiedade e as dificuldades apresentadas pelos acadêmicos quanto a apropriação e a fluência digital ${ }^{10}$. Desse modo, o processo compartilhado de construção dos blogs possibilita a articulação de saberes instrumentais e pedagógicos implicados na abordagem dessa ferramenta multimídia, promovendo a apropriação de aprendizagens de forma colaborativa.

Nos últimos encontros da disciplina solicitamos aos estudantes a socialização das aprendizagens construídas no semestre, por meio do compartilhamento da última postagem inserida nos blogs. Nesses momentos de fechamento da disciplina, os acadêmicos

\footnotetext{
${ }^{8}$ Segundo Gomes (2005), um blog é uma página da Web que se pressupõe ser atualizada com frequência, a partir da inserção de mensagens, as quais são denominadas posts.

9 Para a construção dos blogs utilizamos o servidor "Blogger" ou "Blogspot", disponibilizado gratuitamente pelo Google aos internautas.

${ }^{10}$ De um modo geral, inicialmente, constatamos em todas as turmas resistência e dificuldades diante do uso das tecnologias digitais. Entretanto, no decorrer das oficinas, os estudantes tendem a familiarizar-se e apropriar-se dessas ferramentas. Na tentativa de atenuar as dificuldades identificadas, criamos tutoriais que contém instruções pormenorizadas para orientá-los no processo de construção, atualização e exploração dos diversos recursos disponibilizados pela plataforma empregada para a construção dos blogs.
} 
também apresentaram brevemente seus blogs, discorrendo de forma sucinta sobre as demais postagens e produções realizadas no semestre. Ao final do semestre letivo podemos perceber significativos avanços no processo de apropriação conceitual e fluência digital, uma vez que os licenciandos, de forma geral, evidenciam criatividade e autonomia para operarem com a ferramenta e para refletirem com propriedade sobre os conceitos estudados e suas implicações pedagógicas. Isso pode ser verificado no relato que segue:

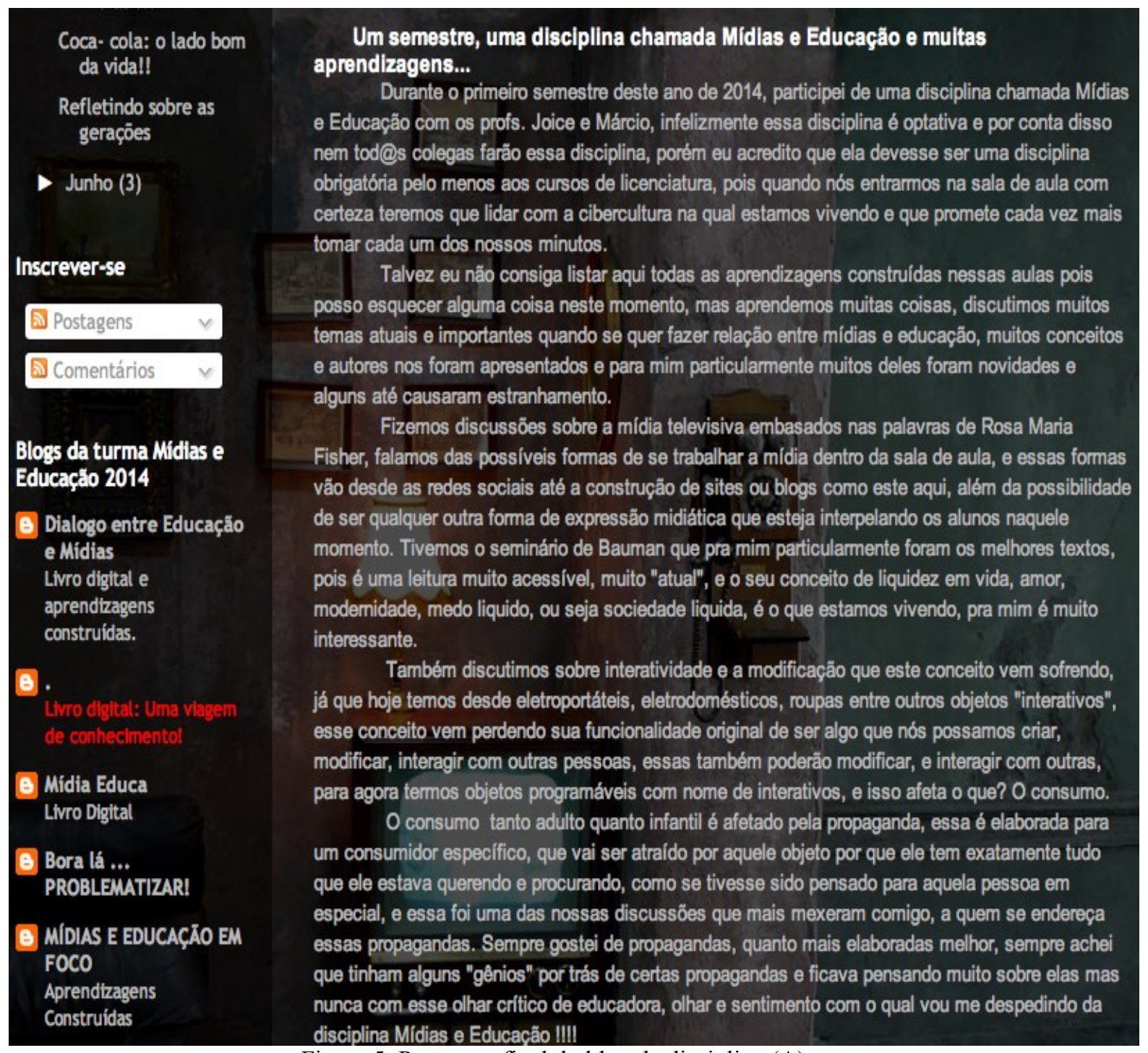

Figura 5: Postagem final do blog da disciplina (A).

Fonte: Arquivo pessoal dos pesquisadores.

Ainda nesta última postagem os estudantes mencionam de forma recorrente o quanto a disciplina contribui para sua formação, ao possibilitar a reflexão sobre questões fundamentais para sua atual ou futura prática pedagógica. Alguns estudantes chegam a relatar que matriculam-se na disciplina devido à obrigatoriedade de cursar uma disciplina optativa, mas surpreendem-se positivamente com a proposta, outros buscaram a disciplina 
devido ao interesse e à percepção acerca da premência de reflexões acerca das demandas educacionais que se configuram no cenário contemporâneo.

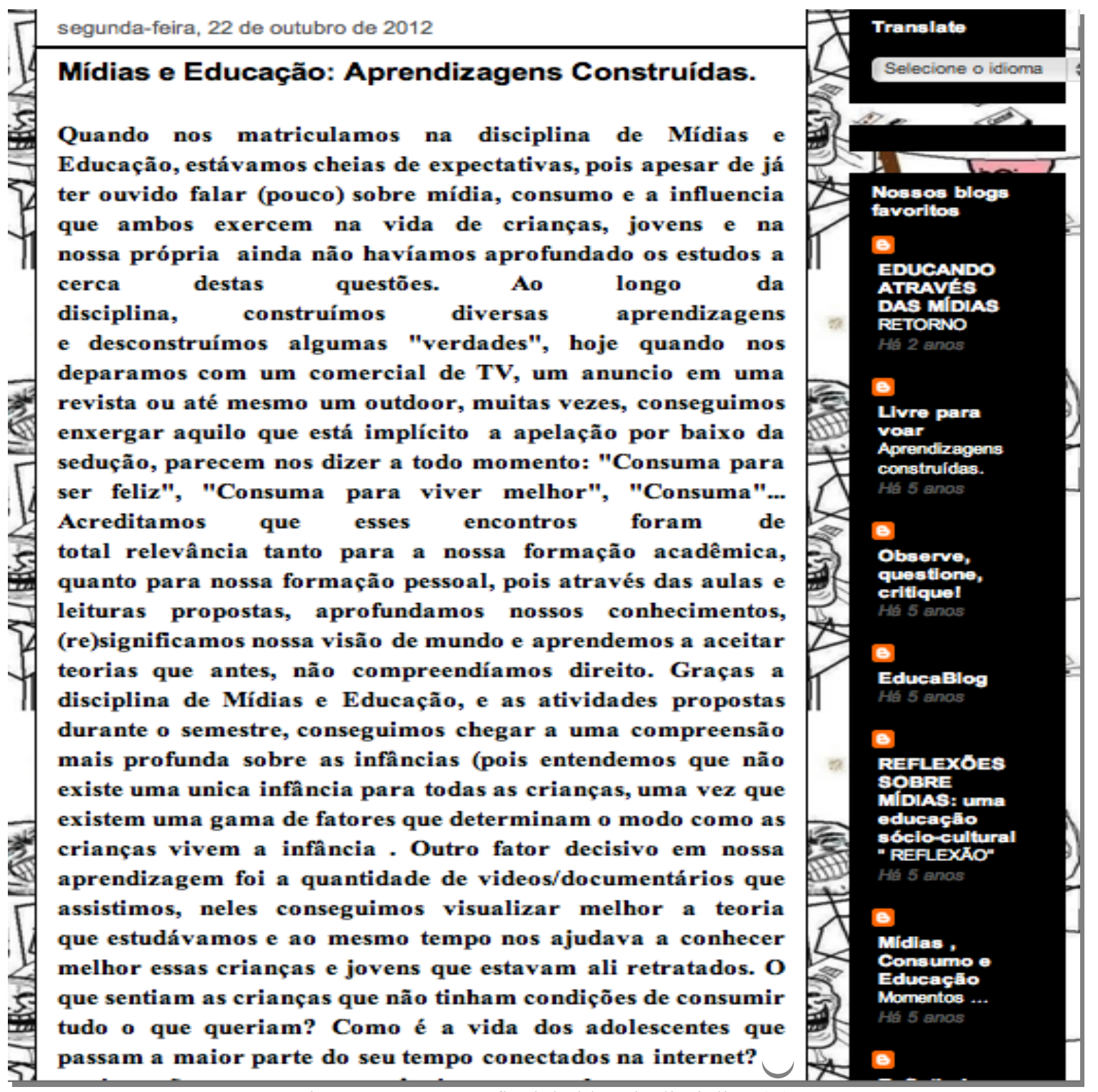

Figura 6: Postagem final do blog da disciplina (B).

Fonte: Arquivo pessoal dos pesquisadores.

O relato acima também deixa explícito o quanto a articulação entre diversas linguagens ampliaram as possibilidades de compreensão e apropriação dos conceitos estudados, evidenciando a diversidade dos modos de aprender e consumir significados que constitui os estudantes na atualidade. $\mathrm{E}$ as tecnologias colocam à disposição dos professores possibilidades de diversificação para abordagem dos conteúdos e do conhecimento, que podem ser integrados e interligados através de ferramentas multimídia. 
O QUE APRENDEMOS SOBRE SER UM PROFESSOR INTERATIVO? SABERES DOCENTES NO CONTEXTO DA CIBERCULTURA

Neste trabalho sistematizamos e socializamos saberes da ação pedagógica construídos na disciplina Mídias e Educação, ofertada a estudantes de cursos de Licenciatura da Universidade Federal do Rio Grande (FURG). Apresentamos reflexões acerca da organização curricular da disciplina e analisamos algumas propostas metodológicas, articuladas as produções dos estudantes.

Após o movimento investigativo e reflexivo desencadeado pela escrita deste artigo, concluímos e defendemos a possibilidade de construção de formas alternativas à tradição pedagógica, pautada na lógica da transmissão e da reprodução de informações, centrada na figura do professor e na uniformidade dos modos de aprender, concepções que se expressam na homogeneidade do material didático e na primazia das linguagens oral e escrita na organização das situações de ensino.

Portanto, o exercício da docência na disciplina Mídias e Educação remete-nos a considerar a relevância de disciplinas e de espaços de reflexão que focalizem as mídias e suas linguagens nos currículos dos cursos de Licenciatura, a fim de habilitarmos os futuros profissionais da educação para os desafios educacionais da atualidade.

Nesse sentido, elencamos alguns saberes que consideramos necessários à docência no contexto da cibercultura: a compreensão acerca do tempo que vivemos, considerando as inextricáveis relações entre educação e sociedade, ou entre as condições históricas e culturais e a constituição dos sujeitos; a ampliação dos entendimentos de alfabetização, leitura e aprendizagem, para além do formato impresso e das linguagens oral e escrita; a concepção das mídias como formas de cultura e aprendizagem e não apenas como recursos neutros empregados para o ensino de conteúdos escolares, o implica questionamento do determinismo tecnológico e da perspectiva instrumental ao pensarmos a abordagem das mídias na escola; o planejamento e a adoção de metodologias dialógicas e interativas, que potencializem a criação, a construção e a apreensão crítica de significados, através de diversas linguagens e modos de expressão; a abertura à reflexão acerca dos processos didáticos desenvolvidos, seus limites e possibilidades, tendo em vista que as mídias estão em constante processo de aperfeiçoamento e transformação.

Há algum tempo atrás, quando realizamos nossos cursos de formação inicial, recordamos que um dos principais desafios elencados pelos professores referia-se ao trabalho pedagógico com a televisão. Muitos profissionais queixavam-se de que as escolas não dispunham de videocassetes e que não tinham acesso a materiais audiovisuais. $\mathrm{Na}$ 
época, algumas iniciativas governamentais para a formação continuada de professores equipavam as escolas com aparelhos de TV e antenas que captavam o sinal de canais educativos, além de fitas com gravações de programas e documentários. Hoje, os estudantes do século XXI chegam as salas de aula equipados com tecnologias móveis, que reúnem diversas funcionalidades com potencial pedagógico quase inexplorado. E nós, professores, o que faremos? Continuaremos interditando o uso de smartphones e bloqueando o acesso à internet na escola? Que tal assumirmos o desafio de repensar nossas concepções e práticas pedagógicas, de reinventar o ensino, para desenvolvermos processos educativos "conectados" com o mundo habitado pelas crianças e jovens contemporâneos? Fica o convite à reflexão.

\section{REFERÊNCIAS}

BAUMAN, Zygmunt. 44 cartas do mundo líquido moderno. Rio de Janeiro: Zahar, 2011.

BELLONI, Maria Luiza. 2012. Infância e internet: a perspectiva da mídia-educação. In: TIC Kids Online Brasil 2012: pesquisa sobre o uso da Internet por crianças e adolescentes. São Paulo: Comitê Gestor da Internet no Brasil, 2013.

BUCKINGHAM, David. Crescer na era das mídias eletrônicas. São Paulo: Edições Loyola, 2007.

ELLSWORTH, Elizabeth. Modos de endereçamento: uma coisa de cinema; uma coisa de educação também. In: SILVA, Tomaz Tadeu da (Org.). Nunca fomos humanos. Belo Horizonte: Autêntica, 2001.

ESPERANÇA, Joice Araújo. Ser criança na sociedade de consumidores: outros tempos, outras infâncias... 2013. 201f. Tese (Doutorado em Educação Ambiental) - Universidade Federal do Rio Grande - FURG, 2013.

FISCHER, Rosa Maria Bueno. Televisão e Educação: fruir e pensar a TV. Belo Horizonte: Autêntica, 2003.

GAUTHIER, Clermont. Ensinar: ofício estável, identidade profissional vacilante. In: GAUTHIER, Clermont et al. Por uma teoria da Pedagogia: pesquisas contemporâneas sobre o saber docente. Ijuí: Editora UNIJUÍ, 1998.

GOMES, Maria João. Blogs: um recurso e uma estratégia pedagógica. Actas do VII Simpósio Internacional de Informática Educativa, Portugal: Leiria, p. 311-315, 2005.

GOMES, Maria João; LOPES, António Marcelino. Blogues escolares: quando, como e porquê?. C. Brito, J. Torres \& J. Duarte. Actas de Weblogs na educação 3 experiências, 3 testemunhos. Setúbal: Centro de Competências CRIE ESE de Setúbal, p. 117-133, 2007.

KELLNER, Douglas. A cultura da mídia - estudos culturais: identidade e política entre o 
moderno e o pós-moderno. São Paulo: EDUSC, 2001.

LÉVY, Pierre. A Revolução contemporânea em matéria de comunicação. Revista FAMECOS: tecnologias do imaginário. Porto Alegre, No. 9: 37-49. Dezembro 1998.

. Cibercultura. São Paulo: Editora 34, 1999.

MOREIRA, Antônio Flávio; CANDAU, Vera Maria. Indagações sobre currículo: currículo, conhecimento e cultura. Brasília : Ministério da Educação, Secretaria de Educação Básica, 2007.

SANTOS, Edméa Oliveira dos; OKADA, Alexandra Lilavati Pereira. A construção de ambientes virtuais de aprendizagem por autorias plurais e gratuitas no ciberespaço. In: $26^{\mathrm{a}}$ Reunião Anual da Associação Nacional de Pós-Graduação e Pesquisa em Educação, Poços de Caldas. ANPEd, 2003.

SILVA, Marco. Indicadores de interatividade para o professor presencial e on-line. Revista Diálogo Educacional. Curitiba, V. 4, No. 12: 93-109, maio/ago. 2004.

Cibercultura e educação: a comunicação na sala de aula presencial e on-line. Revista FAMECOS: mídia, cultura e tecnologia. Porto Alegre, No. 37: 69-74. Dezembro 2008.

SILVA, Tomaz Tadeu da. Documentos de identidade: uma introdução às teorias do currículo. Belo Horizonte: Autêntica, 1999.

TAPSCOTT, Don. A hora da geração digital: como os jovens que cresceram usando a internet estão mudando tudo, das empresas aos governos. Rio de Janeiro: Agir Negócios, 2010 . 
